\title{
Efecto del Método de Colección y Tensión de Oxígeno sobre el Desarrollo de Ovocitos Bovinos Fecundados y Cultivados in vitro
}

\author{
Effect of Recovery Method and Oxygen Tension on Development of Bovine \\ OOCYTES FERTILIZED AND CULTURED IN VITRO
}

\author{
Lenin Benavides I. ${ }^{1}$, Wilfredo Huanca L. ${ }^{1,2}$, Lisbeth Quintanilla M. ${ }^{1}$
}

\section{Resumen}

El objetivo del estudio fue evaluar la influencia del método de colección y la tensión de oxígeno sobre los parámetros de la producción in vitro (PIV) de embriones. En el Experimento 1 se comparó el efecto de dos métodos de colección, aspiración y disección sobre la tasa de división y desarrollo embrionario. La tasa de división a las 72 horas posinseminación fue de 71.4 y $61.0 \%$ con el método de aspiración y de disección, respectivamente $(\mathrm{p}<0.05)$, y sin diferencias significativas en la tasa de blastocistos al día 7 y 9 posfecundación. En el Experimento 2 se compararon dos tensiones de oxígeno en la etapa de cultivo, 5 y $20 \%$ de oxígeno, obteniéndose una tasa de división de 69.7 y $59.7 \%$ para el cultivo con 5 y $20 \%$ de $_{2}$, respectivamente $(\mathrm{p}<0.05)$ y un 29.8 y $19.3 \%$ de blastocistos al día 7 posfecundación bajo 5 y $20 \%$ de $\mathrm{O}_{2}$, respectivamente $(\mathrm{p}<0.05)$, pero sin diferencia estadística en la tasa de blastocistos al día 9 posfecundación. Los resultados sugieren que el método de aspiración y el cultivo con una tensión de oxígeno del 5\% pueden ser considerados como factores adecuados para lograr las condiciones óptimas en el proceso de producción in vitro de embriones bovinos.

Palabras clave: embrión, oxígeno, colección, bovino, PIV

\section{Abstract}

The aim of this study was to evaluate the effect of the recovery method and oxygen tension on in vitro embryo (IVP) production. In Experiment 1 the effect of two recovery methods, aspiration and dissection on embryo division and development rates was evaluated. The 72 hour post-insemination division rate was $71.4 \%$ with aspiration and $61.0 \%$ with dissection $(\mathrm{p}<00.5)$, while no statistical difference was found on blastocyst

\footnotetext{
${ }^{1}$ Laboratorio de Reproducción Animal, Facultad de Medicina Veterinaria, Universidad Nacional Mayor de San Marcos, Lima, Perú

${ }^{2}$ E-mail: whuanca2002@yahoo.com
}

Recibido: 14 de diciembre de 2014

Aceptado para publicación: 4 de julio de 2015 
rates 7 and 9 days post-insemination. In Experiment 2 two oxygen tensions, 5 and 20\%, were compared in the culture stage obtaining higher division rate and 7-day blastocyst rate with $5 \%$ oxygen tension (69.7 and $29.8 \%$ respectively) compared with $20 \%$ oxygen tension (59.7 and $19.3 \%$ respectively). The results suggest that the aspiration recovery method and $5 \%$ oxygen tension must be considered to achieve optimal conditions for in vitro embryo production.

Key words: embryo, oxygen, collection, bovine, IVP

\section{INTRODUCCIÓN}

El mejoramiento de los sistemas de cultivo in vitro son importantes para la producción de embriones con alta capacidad de desarrollo (Hansen et al., 2004). La producción in vitro de embriones implica la colección de ovocitos inmaduros mediante punción (Kane, 2003) o por disección de los folículos (Carolan et al., 1994), maduración in vitro, fecundación in vitro y cultivo embrionario in vitro (Kane, 2003). Si bien existe controversia sobre las ventajas de la disección, esta puede ser importante para la colección de ovocitos inmaduros donde el Complejo Ovocito-Cumulus (COC) no está sobre un pedículo como ocurre con los ovocitos maduros, donde es más difícil desalojarlos desde las capas de granulosa (Fry et al., 1996).

Existe evidencia que indica que la concentración de oxígeno influye en el desarrollo embrionario, aunque aún existen aspectos controversiales (Leese et al., 1998). Cambios en la tensión de oxígeno observados en el oviducto y útero indican que un mecanismo sistémico es el responsable, en lugar de acciones locales de los embriones en crecimiento (Bavister et al., 1983). La capacidad de desarrollo de embriones cultivados en medios modificados como el SOF a $5 \%$ de $\mathrm{O}_{2}$ declina cuando son cultivados al $20 \%$, señalándose que la producción de interferón es similar a la producida bajo condiciones in vivo (Gyu-Jin et al., 2007).

Existen controversias respecto a si las bajas concentraciones de oxígeno son benéfi- cas durante la maduración del ovocito (Harvey, 2007). Clark et al. (2006) proponen un modelo de disminución paulatina de la presión de oxígeno a medida que avanza la formación del embrión, en tanto que Harvey et al. (2002) plantean que los embriones humanos y bovinos podrían establecer una gradiente significativa que lleva a la anoxia en el centro del embrión.

A pesar de estas observaciones, los embriones de la mayoría de especies son cultivados en condiciones cercanas a la atmosférica ( $20 \%$ de oxígeno) o a $5 \%$ de oxígeno sin que lleguen a presentar los cambios dinámicos en la concentración de oxígeno que se observan in vivo (Harvey, 2007). Así, Oyadama y Fukui (2004) reportan mejores resultados con $20 \%$ de oxígeno durante la maduración in vitro en bovinos, mientras que otros autores (Nagao et al., 1994; Hashimoto et al., 2000; Van Soom et al., 2002) demuestran que reduciendo la concentración de oxígeno a $5 \%$ se obtiene un mayor número de oocitos divididos que alcanzaron el estado de blastocisto y mayor número de células por blastocisto.

El efecto positivo de las bajas concentraciones de oxígeno es, además, evidente en lo que respecta al metabolismo embrionario. Se ha demostrado que incrementa la utilización de la glucosa y oxidación de piruvato en ratones, evidenciado por un incremento en la producción de $\mathrm{CO}_{2}$ y lactato (Khurama y Wales, 1989; Hooper et al., 2001). Asimismo, un reducido contenido de $\mathrm{H}_{2} \mathrm{O}_{2}$ en embriones porcinos cultivados bajo $5 \%$ de oxígeno está asociado con la reducción de la 
fragmentación del ADN (Kitagawa et al., 2004).

La adaptación a la hipoxia involucra un amplio rango de respuestas incluyendo expresión génica, funciones metabólicas alteradas y activación alterada de canales iónicos. La habilidad de responder a los cambios de la tensión de oxígeno dentro de un rango fisiológico depende de la activación de una familia de factores de transcripción conocida como factores inducibles por hipoxia (HIF) (Semenza, 2000). Los HIF son considerados como importantes reguladores del desarrollo embrionario en un ambiente in vivo, de modo que su activación podría ser importante para la adaptación de embriones in vitro a un ambiente reducido en oxígeno similar al encontrado naturalmente (Harvey, 2007).

El objetivo del presente estudio fue evaluar el efecto del método de colección de ovocitos (aspiración o disección folicular) y la tensión de oxígeno (5 y 20\%) sobre el desarrollo embrionario en ovocitos bovinos cultivados in vitro.

\section{Materiales y Métodos}

\section{Lugar de Estudio}

Los experimentos se realizaron en la sección de Biotecnología Reproductiva del Laboratorio de Reproducción Animal, Facultad de Medicina Veterinaria, Universidad Nacional Mayor de San Marcos, Lima, Perú.

\section{Colección y Procesamiento de Muestras}

Se colectaron ovarios de animales beneficiados en un camal de la ciudad de Lima, ubicado a $2.7 \mathrm{~km}$ del laboratorio, sin considerar el estado reproductivo del animal. Los ovarios fueron colocados y transportados en un termo conteniendo solución salina $0.9 \%$ suplementada con antibiótico antimicótico (A5955, Sigma), y mantenido a una temperatura inicial de $37^{\circ} \mathrm{C}$.

Se seleccionaron los ovocitos que presentaron citoplasma homogéneo y finamente granulado, el cual debía llenar por completo el espacio delimitado por la zona pelúcida; además, debían estar cubiertos por múltiples y uniformes capas compactas de células del cúmulo (Bertoldo et al., 2010).

Los ovocitos fueron colectados mediante aspiración o disección, madurados en medio TCM-199 (Sigma M2520), suplementado con PVP (Polivinilpirrolidone) (Sigma P0930), $100 \mathrm{mM}$ piruvato sódico, $5 \mathrm{mg} / \mathrm{m}$ gentamicina (Sigma G1264), 20 mg/ml de FSH (hormona folículo estimulante), $10 \mu \mathrm{g} / \mathrm{ml} \mathrm{hCG} \mathrm{y} 1 \mathrm{mg} /$ $\mathrm{ml}$ de estradiol (Sigma E2758), por $24 \mathrm{~h} \mathrm{a}$ una temperatura de $39{ }^{\circ} \mathrm{C}, 5 \%$ de $\mathrm{CO}_{2}, 20 \mathrm{o}$ $5 \%$ de $\mathrm{O}_{2}$ y máxima humedad relativa.

Al término de las 24 h en maduración, los ovocitos fueron trasladados a un medio de fecundación. Para ello, fueron lavados tres veces en medio TL-Hepes de pre-fecundación suplementado con $3 \mathrm{mg} / \mathrm{ml}$ de BSA (albúmina sérica bovina), $100 \mathrm{mM}$ de piruvato y $5 \mathrm{mg} / \mathrm{ml}$ de gentamicina y posteriormente trasferidos a gotas de $40 \mu 1$ de medio de fecundación TL-Stock suplementado con $6 \mathrm{mg} / \mathrm{ml}$ de BSA, $100 \mathrm{mM}$ de piruvato y $5 \mathrm{mg} / \mathrm{ml}$ de gentamicina. La fecundación in vitro se realizó con semen comercial congelado en pajillas.

Al finalizar el periodo de fecundación, los presuntos zigotos fueron retirados de las gotas de fecundación e introducidos en gotas de $30 \mu 1$ de medio de cultivo KSOM-AA (Potassium Simplex Optimized Medium). La proporción de zigotos que se dividieron fue evaluada a las $72 \mathrm{~h}$ posfecundación y luego fueron trasladados al medio de cultivo SOF (Synthetic Oviduct Fluid). En los días 7 a 9 posfecundación se observaron los estadios de blastocisto y blastocisto expandido. 


\section{Diseño Experimental}

\section{Experimento 1: Evaluación de la técnica de obtención de ovocitos}

Tuvo por objetivo comparar dos técnicas de colección de ovocitos (aspiración manual y disección) sobre la tasa de división y la tasa de desarrollo embrionario hasta los estadios de blastocisto y blastocisto expandido en los días 7 y 9 posfecundación, respectivamente.

\section{Experimento 2: Evaluación de la tensión de oxígeno en el cultivo embrionario}

Tuvo por objetivo comparar el efecto de dos tensiones de oxígeno (5 y 20\%) sobre la tasa de división posfecundación y la tasa de desarrollo embrionario hasta los estadios de blastocisto y blastocisto expandido en los días 7 y 9 posfecundación, respectivamente.

\section{Análisis Estadístico}

Los resultados fueron expresados como porcentajes. Los datos del experimento $1 \mathrm{se}$ analizaron con la prueba de «t» de student para muestras independientes de diferentes varianzas (aproximación de Welch). Asimismo, para determinar diferencias en cantidades de ovocitos sometidos a cultivo según su calidad (experimento 1), así como por porcentajes de blastocistos obtenidos (experimentos 1 y 2) se realizó la prueba de Chi cuadrado de Pearson. Todos los resultados se expresaron con un nivel de significancia de $95 \%$ $(p<0.05)$. Se utilizó el programa estadístico STATA 10.0 (Stata Corp.).

\section{Resultados}

En el Experimento 1 se utilizaron 116 ovarios para la técnica de aspiración y 88 ovarios para la técnica de disección. Se recuperaron 772 ovocitos con el método de aspiración y 1134 con el método de disección, pero luego del proceso de selección, se utili- zaron 451 y 449 ovocitos, procedentes de aspiración y disección, respectivamente. Los ovocitos fueron categorizados de acuerdo a su calidad como A (excelente), B (buena) y C (mediana), según Bertoldo et al. (2010).

Los resultados muestran una diferencia en el número de ovocitos recuperados por ovario ( $\mathrm{p}<0.05)$, a favor del método de disección (Cuadro 1). Además, hubo diferencia significativa en el porcentaje de ovocitos divididos a las 72 horas de la fecundación a favor del método de aspiración ( $\mathrm{p}<0.05$ ), pero no se registraron diferencias entre ambos métodos de colección en el porcentaje de blastocistos ni en el porcentaje de blastocistos expandidos (Cuadro 1). Por otro lado, no hubo diferencias significativas entre categorías de ovocitos según el método de colección (Cuadro 2).

Los resultados del Experimento 2 muestran que existe diferencia entre la proporción de zigotos divididos y en la proporción de blastocistos al día 7 posfecundación por efecto de la tensión de oxígeno $(\mathrm{p}<0.05$, Cuadro 3 ); sin embargo, estas diferencias desaparecen en el día 9 posfecundación.

\section{Discusión}

El método de disección mostró una ventaja inicial sobre el método de aspiración manual al presentar una media de ovocitos recuperados por ovario significativamente mayor; sin embargo, no hubo diferencias significativas en el número de ovocitos aptos para cultivo in vitro y, más aún, la proporción de ovocitos divididos luego de la fecundación fue estadísticamente superior en el grupo de aspiración manual $(\mathrm{p}<0.05)$.

Este resultado podría estar relacionado al hecho de que los ovocitos obtenidos por aspiración sufren menos estrés de manejo por parte del operario, requieren de menos tiempo y permiten mejores condiciones de limpieza (Arav, 2000). Además, con el método de 
Cuadro 1. Resultados del uso de dos métodos de obtención de ovocitos de bovino en el cultivo de embriones in vitro ${ }^{1}$

\begin{tabular}{lcccc}
\hline $\begin{array}{l}\text { Método de } \\
\text { colección }\end{array}$ & $\begin{array}{c}\text { N. }{ }^{\circ} \text { de ovocitos } \\
\text { por ovario }\end{array}$ & $\begin{array}{c}\text { Divisiones a las } \\
72 \text { hpi }(\%)^{2}\end{array}$ & $\begin{array}{c}\text { Blastocistos a } \\
\text { los } 7 \text { dpi }(\%)^{3}\end{array}$ & $\begin{array}{c}\text { Blastocistos } \\
\text { expandidos a los } \\
9 \text { dpi (\%) }\end{array}$ \\
\hline Aspiración & $7.4 \pm 4.7^{\mathrm{a}}$ & $71.4 \pm 6.5^{\mathrm{a}}$ & $17.6 \pm 3.7^{\mathrm{a}}$ & $11.4 \pm 1.9^{\mathrm{a}}$ \\
Disección & $14.5 \pm 4.4^{\mathrm{b}}$ & $61.0 \pm 8.6^{\mathrm{b}}$ & $22.9 \pm 9.3^{\mathrm{a}}$ & $12.1 \pm 3.9^{\mathrm{a}}$ \\
\hline
\end{tabular}

${ }^{a, b}$ Superíndices diferentes dentro de columnas indican diferencia entre tratamientos $(p<0.05)$

${ }^{1}$ Número de réplicas $=5$

2 hpi: horas posinseminación

${ }^{3} \mathrm{dpi}$ : días posinseminación

Cuadro 2. Número de ovocitos de bovino según calidad obtenidos por aspiración o disección sometidos a cultivo in vitro ${ }^{1}$

\begin{tabular}{ccccc}
\hline \multirow{2}{*}{ Método de colección } & \multicolumn{5}{c}{ Calidad del Ovocito $^{2}$} \\
\cline { 2 - 5 } & A & B & C & Total \\
\hline Aspiración & 79 & 286 & 86 & 451 \\
Disección & 83 & 253 & 113 & 449 \\
\hline
\end{tabular}

${ }_{2}^{1}$ Número de réplicas $=5$

${ }^{2}$ No se observó diferencia estadística entre grupos según la calidad del ovocito

Cuadro 3. Resultados del uso de dos tensiones de oxígeno en el cultivo de embriones in vitro

\begin{tabular}{ccccc}
\hline $\begin{array}{c}\text { Tensión de } \\
\text { oxígeno }\end{array}$ & $\begin{array}{c}\text { Ovocitos en } \\
\text { cultivo (n) }\end{array}$ & $\begin{array}{c}\text { Divisiones a las } \\
72 \text { hpi }(\%)\end{array}$ & $\begin{array}{c}\text { Blastocistos a } \\
\text { los 7 dpi (\%) }\end{array}$ & $\begin{array}{c}\text { Blastocistos } \\
\text { expandidos a los } \\
9 \text { dpi (\%) }\end{array}$ \\
\hline $5 \%$ & 252 & $69.7 \pm 0.1^{\mathrm{a}}$ & $29.8 \pm 0.01^{\mathrm{a}}$ & $14.5 \pm 0.05^{\mathrm{a}}$ \\
$20 \%$ & 264 & $59.7 \pm 0.1^{\mathrm{b}}$ & $19.3 \pm 0.03^{\mathrm{b}}$ & $9.8 \pm 0.02^{\mathrm{a}}$ \\
\hline
\end{tabular}

a,b Superíndices diferentes dentro de columnas indican diferencia entre tratamientos $(p<0.05)$

${ }^{1}$ Número de réplicas $=4$

disección, la búsqueda de los ovocitos aptos se dificulta debido a la mayor cantidad de detritus en el medio. Asimismo, el número de ovocitos descartados que fueron obtenidos por el método de disección fue mucho mayor, ya que la disección implica un manipuleo más rudo y prolongado y en este trámite los ovocitos pueden perder o alterar sus capas de células del cumulus; además, al diseccionar la corteza ovárica se estarían recuperando también ovocitos más inmaduros cuyo antro aún no es visible y no estarían en condiciones 
de someterse a un proceso de cultivo in vitro (Arlotto et al., 1990).

Los resultados del Experimento 2 mostraron un mejor comportamiento de los ovocitos fecundados y mantenidos bajo condiciones de baja tensión de oxígeno, corroborando otros estudios donde se comparó la eficiencia del 5 y el $20 \%$ de $\mathrm{O}_{2}$ en términos de formación de blastocistos en bovinos (Lim et al., 1999) y embriones humanos (Dumoulin et al., 1999). Otro hallazgo interesante es que los embriones cultivados bajo $5 \%$ de $\mathrm{O}_{2}$ mostraron mayor porcentaje de embriones divididos, indicando que podría llegar a tener un incremento de la producción total de blastocistos. Hay que considerar que durante el desarrollo in vivo, los embriones mamíferos están sujetos a una tensión de $9 \%$ de $\mathrm{O}_{2}$ en el oviducto, seguido de una tensión de $2 \%$ hacia el día tres de la ovulación (Fischer y Bavister, 1993).

El número de blastocistos obtenidos no sería el único parámetro diferencial entre las tensiones de oxígeno, pues es posible que la calidad de embriones cultivados bajo $20 \%$ de $\mathrm{O}_{2}$ sea inferior a aquellos obtenidos bajo 5\% de $\mathrm{O}_{2}$. El estadio de divisiones en embriones bovinos puede estar sujeto a proteínas derivadas maternalmente para su primera división en la etapa de divisiones, pero entonces la transición zigótico-maternal debe ocurrir y la expresión génica debería ser activada en los embriones (Memili y First, 2000). Aún debe determinarse si esta transición o la activación que prosigue de la expresión génica del embrión se afectan por una alta tensión de oxígeno. En cualquier caso, ha sido reportado que los embriones vecinos en una gota de cultivo pueden influenciar en la cantidad de oxígeno disponible (Trimarchi et al., 2000), lo cual podría ser la razón para un mejor desarrollo de embriones cultivados en grupos versus embriones solitarios (Yuan et al., 2000).

Se ha propuesto que el efecto beneficioso de un co-cultivo con células somáticas sobre el desarrollo embrionario podría ser causado por las bajas tensiones de oxígeno en la vecindad del embrión (Bavister, 1988). Los mecanismos de acción no han sido esclarecidos pero se postula que la tensión de oxígeno interviene en la regulación de la proliferación celular y la diferenciación durante los estadios tempranos del desarrollo embrionario. Aunque las tensiones de oxígeno durante el tránsito oviductual son del 9\% (Fischer y Bavister, 1993), esto es mucho más bajo que el $20 \%$ de $\mathrm{O}_{2}$ presente en condiciones atmosféricas.

Las condiciones atmosféricas de oxígeno podrían dañar el desarrollo embrionario mediante el incremento de los niveles de especies reactivas de oxígeno (ROS) en la célula (Parchment, 1993). Los niveles de ROS están elevados en embriones cultivados bajo $20 \%$ de $\mathrm{O}_{2}$ (Adachi et al., 2001) y están probablemente implicados en el crecimiento retardado de los embriones in vitro (Tarin, 1996). Además, se ha reportado que la tasa de células apoptóticas aumenta significativamente en embriones cultivados bajo $20 \%$ de $\mathrm{O}_{2}$ (Van Soom et al., 2002). Por otro lado, la influencia del oxígeno sobre los factores inducibles por hipoxia (Semenza, 2000) parece brindar una explicación más veraz sobre el rol que tiene la tensión de oxígeno en el desarrollo embrionario. Asimismo, se reporta que embriones en estado de blastocisto consumen más oxígeno que aquellos de etapas más tempranas (Hooper et al., 2001).

\section{Conclusiones}

- $\quad$ El número de ovocitos recuperados por ovario es significativamente mayor cuando se usa el método de disección ovárica (14.4 \pm 4.4$)$ comparado con la recuperación por aspiración manual $(7.4 \pm 4.7)$.

- La cantidad de ovocitos cultivables fue equivalente para ambos métodos de colección, pese a haberse obtenido mayor número de ovocitos por ovario con el método de disección. 
- El método de colección de ovocitos no influyó en el porcentaje de blastocistos obtenidos.

- El porcentaje de zigotos divididos al día tres posfecundación fue significativamente mayor bajo una tensión de $5 \%$ de $\mathrm{O}_{2}(69.7 \%)$ que el obtenido a $20 \%$ de $\mathrm{O}_{2}(59.7 \%)$.

- El porcentaje de blastocistos al día siete posfecundación obtenidos con una tensión de $5 \%$ de $\mathrm{O}_{2}$ fue significativamente mayor $(27.8 \%)$ que el obtenido a $20 \%$ de $\mathrm{O}_{2}(19.3 \%)$.

\section{Literatura Citada}

1. Adachi S, Ito H, Tamamori-Adachi M, Ono Y, Nazato T, Abe S. 2001. Cyclin $\mathrm{A} / \mathrm{cdk} 2$ activation is involved in hypoxiainduced apoptosis in cardiomyocytes. Circ Res 88: 408-414.

2. Arav A. 2000. Transillumination increases oocyte recovery from ovaries collected at slaughter. A new technique report. Theriogenology 55: 1561-1565.

3. Arlotto T, Leibfried-Rutledge M, First $N$. 1990. Size distribution and meiotic competence of bovine primary oocytes from two locations in the ovary. Theriogenology 33: 188 (Abstr).

4. Bavister B, Liebfried M, Lieberman G. 1983. Development of preimplantation embryos of the golden hamster in a defined culture medium. Biol Reprod 28: 235-247.

5. Bavister BD. 1988. Role of oviductual secretions in embryonic growth in vivo or in vitro. Theriogenology 29: 143-154.

6. Bertoldo M, Holvoake P, Evans G, Grupen C. 2010. Oocyte development competence is reduced in sows during the seasonal infertility period. Reprod Fertil Dev 22: 1222-1229. doi: 10.1071/ RD10093

7. Booth P, Holm P, Callesen H. 2005. The effect of oxygen tension on porcine embryonic development is dependent on embryo type. Theriogenology 63: 20402052.
8. Carolan C, Monaghan P, Gallagher M, Gordon I. 1994. Effect of recovery method on yield of bovine oocytes per ovary and their developmental competence after maturation, fertilization and culture in vitro. Theriogenology 41 : 1061-1068.

9. Clark A, Stokes Y, Lane M, Thompson J. 2006. Mathematical modelling of oxygen concentration in bovine and murine cumulus-oocyte complexes. Reproduction 131: 999-1006.

10. Dumoulin JC, Meijers CJ, Bras M, Coonen E, Geraedts JP, Evers JL. 1999. Effect of oxygen concentration on human in vitro fertilization and embryo culture. Hum Reprod 14: 465-469.

11. Fischer B, Bavister B. 1993. Oxygen tension in the oviduct and uterus of rhesus monkeys, hamsters and rabbits. J Reprod Fert 99: 673-679.

12. Fry R, Niall E, Simpson T, Squires T, Reynolds J. 1996. The collection of oocytes from bovine ovaries. Theriogenology 47: 977-987.

13. Gott AL, Hardy R, Winston R, Léese $H .1990$. Non-invasive measurement of pyruvate and glucose uptake and lactate production by single human preimplantation embryos. Hum Reprod 5: 104-108.

14. Harvey A, Kind K, Thompson J. 2002. REDOX regulation of early embryo development. Reproduction 123: 479486.

15. Harvey A. 2007. The role of oxygen in ruminant preimplantation embryo development and metabolism. Anim Reprod Sci 98: 113-128.

16. Hashimoto S, Minami N, Takakura R, Yamada M, Imai H, Kashima $N$. 2000. Low oxygen tension during in vitro maturation is beneficial for supporting the subsequent development of bovine cumulus-oocyte complexes. Mol Reprod Dev 57: 353-360.

17. Hooper K, Lane M, Gardner D. 2001. Reduced oxygen concentration increases mouse embryo development and oxidative metabolism. Theriogenology 55: 334 (Abstr). 
18. Kane M. 2003. A review of in vitro gamete maturation and embryo culture and potential impact on future animal biotechnology. Anim Reprod Sci 79: 171190.

19. Khurana N, Wales R. 1989. Effects of oxygen concentration on the metabolism of [U-14C] glucose by mouse morulae and early blastocysts in vitro. Reprod Fertil Dev 1: 99-106.

20. Kitagawa Y, Suzuki K, Yoneda A, Watanabe T. 2004. Effects of oxygen concentration and antioxidants on the in vitro developmental ability, production of reactive oxygen species (ROS), and DNA fragmentation in porcine embryos. Theriogenology 62: 1186-1197.

21. Legge M, Sellens M. 1991. Free radical scavengers ameliorate the 2-cell block in mouse embryo culture. Hum Reprod 6: 867-871.

22. Lim JM, Mei Y, Chen B, Godke RA, Hansel W. 1999. Development of bovine IVF oocytes cultured in medium supplemented with a nitric oxide scavenger or inhibitor in a co-culture system. Theriogenology 51: 941-949.

23. McKiernan S, Bavister B. 1990. Environmental variables influencing in vitro development of hamster 2-cell embryos to the blastocyst stage. Biol Reprod 43: 404-413.

24. Memili E, First NL. 2000. Zygotic and embryonic gene expression in the cow: a review of timing and mechanisms of early gene expression as compared with other species. Zygote 8: 87-96.

25. Nagao Y, Saeki K, Hoshi H, Kainuma H. 1994. Effects of oxygen concentration and oviductal epithelial tissue on the development of in vitro matured and fertilized bovine oocytes cultured in protein-free medium. Theriogenology 41: 681-687.
26. Oyamada T, Fukui Y. 2004. Oxygen tension and medium supplements for in vitro maturation of bovine oocytes cultured individually in a chemically defined medium. J Reprod Dev 50: 107117.

27. Parchment RE. 1993. The implications of a unified theory of programmed cell death, polyamines, oxyradicals and histogenesis in the embryo. Int $\mathrm{J}$ Dev Biol 37: 75-83.

28. Semenza G. 2000. Expression of hypoxia-inducible factor 1: mechanisms and consequences. Biochem Pharmacol 59: 47-53.

29. Tarin JJ. 1996. Potential effects of age-associated oxidative stress on mammalian oocytes/embryos. Mol Hum Reprod 2: 717-724.

30. Thompson J, Simpson A, Pugh P, Donnelley P, Tervit H. 1990. Effect of oxygen concentration on in vitro development of preimplantation sheep and cattle embryos. J Reprod Fertil 89: 573-578.

31. Trimarchi JR, Liu L, Porterfield DM, Smith PJS, Keefe D. 2000. Oxidative phosphorylation-dependent and independent oxygen consumption by individual preimplantation mouse embryos. Biol Reprod 62: 1866-1874.

32. Van Soom A, Yuan Y, Peelman L, de Matos D, Dewulf J, Laevens $H$, de Kruif A. 2002. Prevalence of apoptosis and inner cell allocation in bovine embryos cultured under different oxygen tensións with or without cysteine addition. Theriogenology 57: 1453-1465.

33. Yuan YQ, Van Soom A, Laevens $H$, Coopman F, Peelman LJ, de Kruif A. 2000. Single embryo culture affects hatching rate in bovine in vitro-produced embryos. Theriogenology 53: 307 (Abstr). 